\title{
Improvement of Conversion Efficiency and Enhancement in Output Power of Solar Panel
}

\author{
Chandra Kant Sahu ${ }^{1}$, Saurabh Patel ${ }^{2}$ \\ ${ }^{1,2}$ Department of Electrical and Electronics Engineering, Lovely Professional University, Phagwara, Punjab
}

\begin{abstract}
Concentrating photovoltaics (CPV) is used to integrate the extraction of light energy and thermal energy. The water cooling system is proposed in this paper provides an effective cooling by circulating cold water to remove heat from the PV systems. The use of a water circulation cooling system improves photovoltaic power systems $2 \%$ to $15 \%$ and increases the efficiency of electricity production of photovoltaic $2.29 \%-3.37 \%$. Through the combined use of photovoltaic and thermal techniques, the total energy of the entire system can be improved by $37 \%-59 \%$, even taking into account the cooling system power consumption. A solar hybrid system is designed to use novel photovoltaics (PV), thermoelectric modules (TE), and hot water (HW) through a multilayer of the building envelope. Water pipes are cast into a functionally graded material layer to serve as a heat sink, which allows because heat water easily transfer through some surface rich in aluminum, while being isolated by a polymer rich background. Compared to traditional solar panels, this design can achieve efficiencies with increased production of electricity and the use of thermal energy. Based on the limitations of the theoretical conversion efficiency, PV / TE / HW system exceeds PV / HW and traditional photovoltaic systems with $30 \%$ more output power.
\end{abstract}

Keyword: FGM, PLTC, PV cells, TE Layer, CPV, HDPE

\section{Introduction}

The latest systems, renewable energy has grown rapidly worldwide, and some renewable energy industries such as solar and wind power have developed to an annual growth rate of $20 \%$ or more. Adding renewable energy sources diversified energy and it contributes to climate change of direction; Therefore, renewable energy provides important alternative energy sources that promote sustainable development. In recent years, due to fluctuations international oil prices, the development of renewable energy It attracted widespread attention in many countries and has become the focus of the international energy sector. Currently, at this time, many developed countries have invested in research and the development of renewable energy sources. The development renewable energy promotes energy security, reducing pollution and depletion of energy is attenuated.

Solar energy has been considered as a promising solution to energy and environmental, global challenges the global threat. We suffer from energy crisis and environmental pollution caused by burning fossil fuels. The sun provides energy to earth with a capacity of $1.2 \times 10^{5} \mathrm{TW}$, which is about $10^{4}$ times the rate at which the man civilization currently produces and uses. In addition, solar energy is clean, reliable, renewable and environment.

Direct and efficient use of solar energy has been discharged priority to address energy and environmental problems. Photovoltaic (PV) can directly convert solar energy into electrical energy with zero emissions. Since the first recognition in 1839, photovoltaic technology has made great progress. However, there is still a lot of effort aspects of improving efficiency and reducing costs. For the only technology attachment If a single crystal, the conversion efficiency is still less than $30 \%$.Thus,much of the solar energy is lost through heat dissipation. While some emerging technologies can significantly improve the efficiency of energy use, such as multi junction cells, the optical frequency shift multiple excite on generation cells the level of multiple energy cells, support hot cells, and PV system concentration, these technologies require expensive and complex operating conditions, and therefore they are not used commercially Roof panel solar still.

Solar thermal technology provides another way to use the thermal energy of insolation. Solar thermal collectors have been applied to domestic products (bathroom, kitchen, space heating, pool heating, etc.) and commercial (boiler preheating, hospitals, etc.). However, applications of solar energy. Thermal sensors are limited by the application of heat and architectural aesthetics. Thermoelectric module (TE) may be a good candidate for recovery of thermal energy. You can directly convert thermal energy into electricity, which is determined by the temperature difference between two sides of the module. As a semiconductor device without no moving parts, aTE generator can be completely silent, extremely reliable. It can be used for years to provide electricity. The power. However, existing TE modules are quite expensive and their conversion efficiencies are low in technology not concentrated solar energy. Emerging Nano technologies in TE cells You can change this and allow a new type of solar energy the technology. Normally, the energy payback time (PLTS) for solar thermal energy is lower than that of photovoltaic systems. The photovoltaic system can PLTS reduced by the use of a hybrid system incorporating PV with solar thermal components such as (HW) of hot water pipes and TE. Combining two or three of these approaches are a simple superposition of the materials and costs, but provides a viable solution to significantly increase the overall efficiency of energy use while reducing the disadvantages of one approach. PV-thermal collectoral lows heat collection while it is improving utilization efficiency PV by controlling the temperature of the photovoltaic modules. Currently, some groups have studied the performance of PVTE hybrid systems, which provide good justifications solar hybrid approaches. 


\section{International Journal of Science and Research (IJSR) \\ ISSN (Online): 2319-7064}

Index Copernicus Value (2013): 6.14 | Impact Factor (2014): 5.611

This paper presents a novel hybrid solar system PV/TE/HW presents including photovoltaic cells mono crystalline bismuthtelluride (Bi2Te3). TE HW modules tubes and cast in a material gradient function (FGM).The performance of this multi-hybrid system predicted and characterized. The test results show solar hybrid energy recovery performance it is plausible that traditional solar panels. The design quantum well (QW) and quantum dots (QD)TE The modules could increase the production of electricity and, therefore, for increased profitability.

\section{Design of Hybrid Solar Panel}

A novel hybrid solar panel has been designed for PV use, TE, and DD via a multilayer configuration, which is schematically illustrated in Fig. A surface layer and below the PV TE photoelectric transfer layer energy and electricity respectively. TE layer is attached on a plastic timber plate through an intermediate layer of the FGM. FGM contains aluminum (Al) powder dispersed in a high density polyethylene matrix with a graded micro structure seen in the left top (HDPE) in Fig. Water pipes are cast into the FGM to control the panel temperature. Plastic wood, recycled polymer materials, provides supports the mechanical load and the thermal insulation of the building envelope. Design innovations are summarized as follows.

1) The temperature difference between the photovoltaic module and the water tubes provides a significant temperature gradient within the TE side for improved efficiency in the use of TE.

2) HW, whose temperature is controlled in part by flow rate, can be directly utilized by water heating systems for home use.

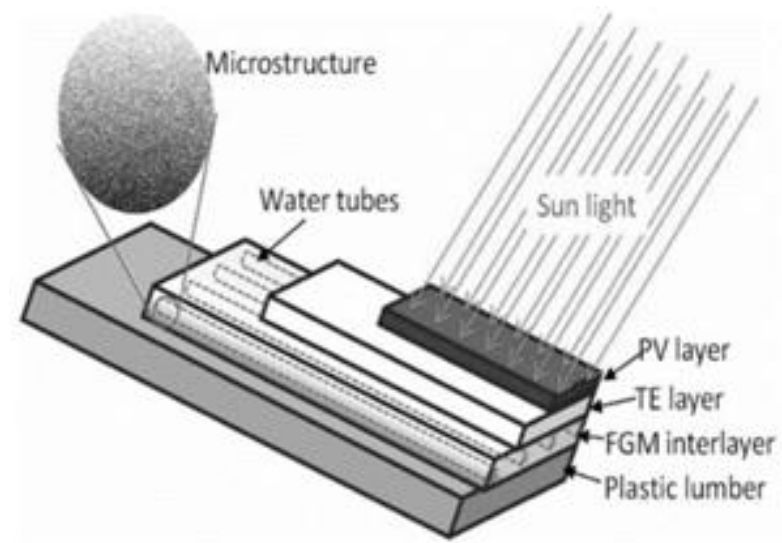

Figure 2.1: Novel Hybrid Solar Panel

3) Due to the temperature control in the roof, temperature of room can be significantly reduced and thermal comfort in the building can be improved.

4) Different materials and components will be chemically and physically compatible to ensure durable end product.

5) A high percentage of $\mathrm{Al}$ powder is quickly transferred heat to the water pipes, but below the heat conduction is blocked by the plastic substrate HDPE timber.

6) The thin film PV layer improves heat conduction and structural integrity within the panel, and protects the polymer materials under UV radiation.

7) The plastic wood substrate provides mechanical and structural support for the upper layers and thermal insulation for indoor air as well as to prevent water condensation.

\section{Theory and Mat Lab Design of solar panel}

In the research first I have find the mathematical equation for the design of solar panel. In this I have made the mathematical model that contains the all parameters equation of the solar panel. Using all those equations I have get the output curve of the solar cell which can define the value of output and the efficiency of the cell. In first I have to get the all available values of data that required in the equation model. I have get the predetermine value of the variables those are used in the solar cell equation.

The solar cell equation is same as the single diode operation equation. For that I consider the single diode as the cell of panel and start the .m file modelling

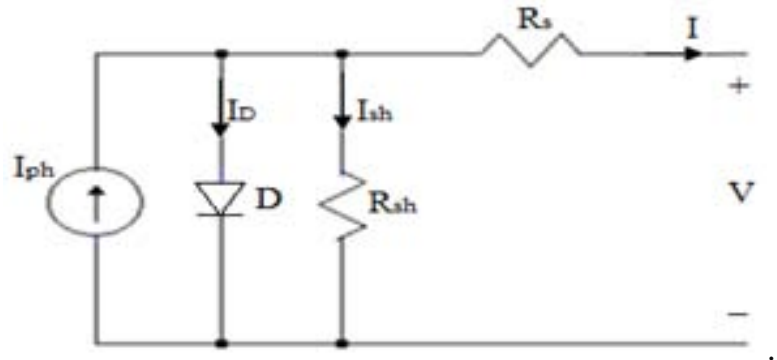

Figure 3.1: Single diode solar cell Equivalent Circuit

The given circuit is representing the equivalent circuit of the PV cell. It contains the current source, diode, series and shunt resistance. The current equation to the load is given by:

$$
I=I_{p h}-I_{s}\left(\exp \frac{q\left(V+R_{s} D\right)}{N K T}-1\right)-\frac{\left(V+R_{s} l\right)}{R_{s h}} \ldots \ldots
$$

In this equation, $I_{p h}$ is the photocurrent, $I_{s}$ is the reverse saturation current of diode, $q$ is the charge, $V$ is the voltage across diode, $T$ is the temperature, $N$ is the ideal factor of diode, and $R_{s}$ and $R_{s h}$ is the series and shunt resistance.

$$
I_{s}(T)=I_{s}\left(\frac{T}{T_{\text {nom }}}\right)^{3} \exp \left[\left(\frac{T}{T_{\text {nom }}}-1\right) \frac{E_{g}}{N \cdot V_{t}}\right] \ldots .
$$

The diode reverse saturation current is given by the equation (2) that may vary according to the temperature. Where Eg is the band gape energy of the semiconductor and $\mathrm{Vt}$ is the thermal voltage and the Tnom is the nominal voltage.

$$
I_{p h}=\left[I_{s c}+K_{i}(T-298)\right] \frac{\beta}{1000}
$$

Equation (3) is represent the photocurrent which is dependent on the radiation and temperature. In this equation $\mathrm{Ki}=0.0017 \mathrm{~A} /{ }^{0} \mathrm{C}$ is the cells short circuit current temperature coefficient and $\beta$ is the solar radiation $\left(\mathrm{W} / \mathrm{m}^{2}\right)$. 


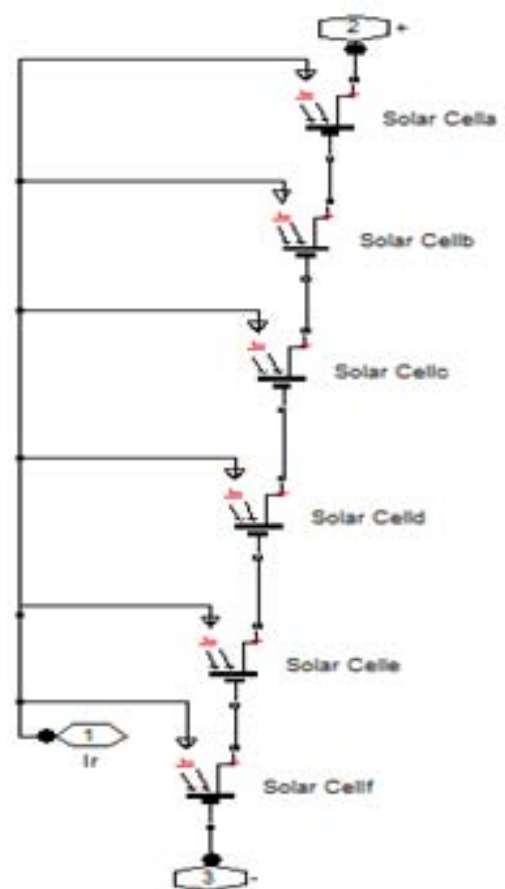

Figure 3.2: Series combined solar cell matlab model

6 solar cells

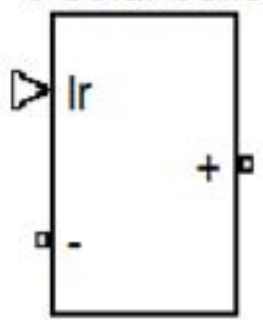

Figure 3.3: Solar cell subsystem

After designing the solar panel, I have design the signal converter that convert the signals from the one form to the another form. The signal converter is convert the physical signal to the unit less Simulink signal so that the output will formed. The signal converter contains the current sensor and the voltage sensor that will sense the voltage and current signal generated by the solar system. That both sensors are forward these signals to the physical signal to simulation signal converter so that we can take the output in the display. The output terminal of the converter is connected with the display circuit and with the scope. In the scope only parallel line show because the voltage and current produce by the solar panel is DC so it shows the parallel line. In the output we can measure the total power output using the product of both voltage and current. After doing this I try to make theDC to AC control converter that can convert the DC signal to the AC signal.

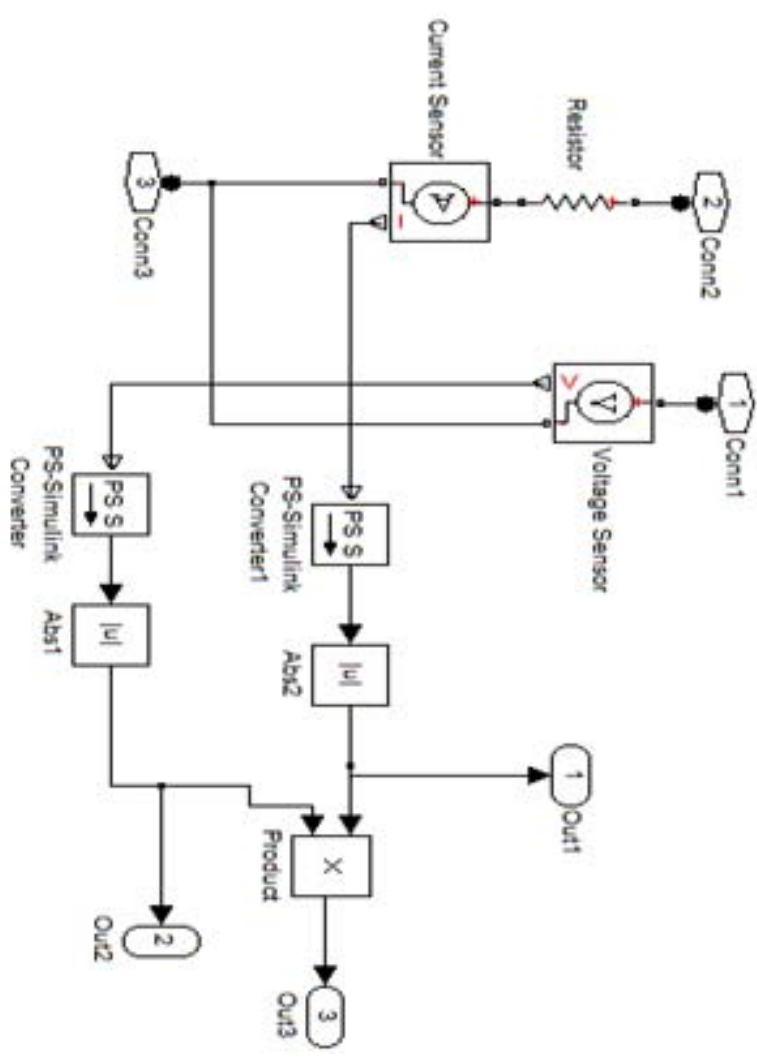

Figure 3.4: Signal converter for solar panel subsystem

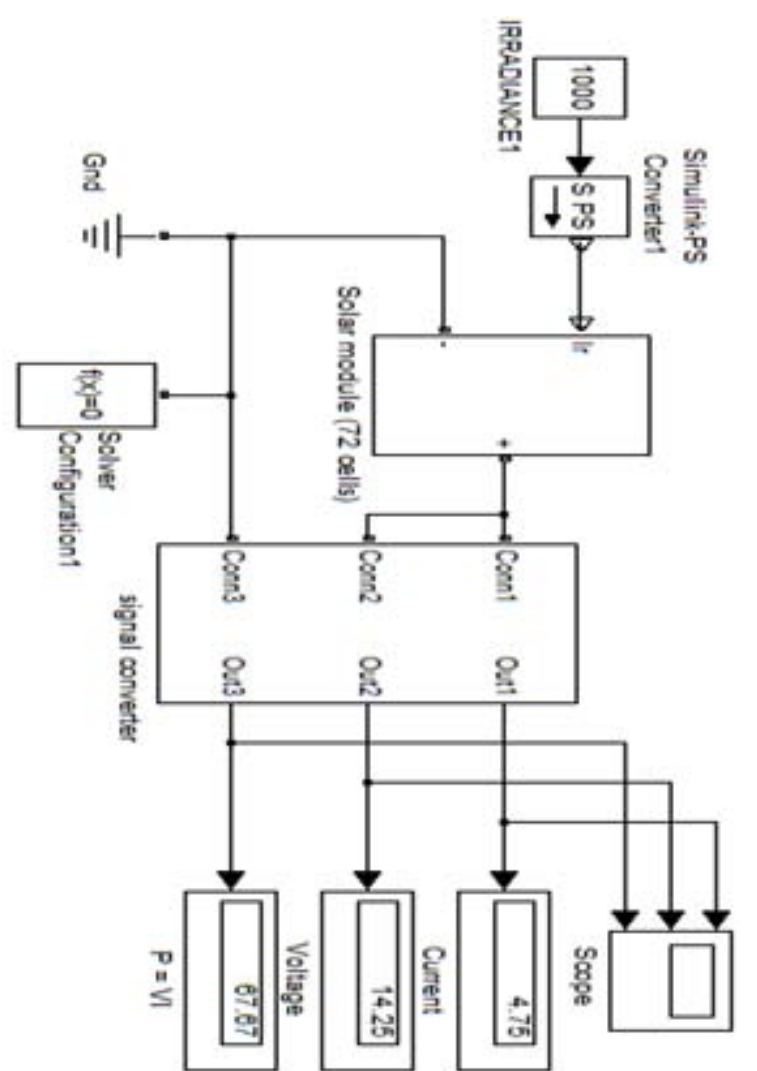

Figure 3.5: Main model of solar panel with the value output

\section{Expected Outcome of Study}

Using this technique, the rate of conversion of the energy conversion is increased by 3-5\% theoretically. When I apply some new technique in the future work it will may increase 


\section{International Journal of Science and Research (IJSR) \\ ISSN (Online): 2319-7064 \\ Index Copernicus Value (2013): 6.14 | Impact Factor (2014): 5.611}

more. When the novel hybrid system and the cooling system worked perfect then the result will be more specific. The Expected results comes after applying this technique are:

1) Improve the rate of change of energy conversion.

2) Increase the performances of the system.

3) Power quality may improve.

4) More generation may be possible after applying the techniques.

5) The power generated by the solar panel is more efficient.

6) Energy utilization is improving more.

7) The loss of the heat and temperature is also converted into the electricity energy.

8) The cooling system connected with the model is also used for the hot water supply in the buildings in winter season.

9) This technique is also used for the MPPT for the maximum power point tracking.

10) The energy generated by this technique is more economical.

\section{Conclusion}

In this thesis/dissertation work, I have designed the solar panel system. The model is simulated with the help of the MATLAB and Pspice. Then I have designed the advanced solar system that includes the solar PV panels, thermal panels and thermal materials, and the cooling system. That advanced solar system is called the novel hybrid solar panel or the system. In this model to control the function of the system I have designed the controllers and the converter model that can stabilised the system and try to control and convert the system parameter. The converter circuit is used to convert the power output to the desired output. It will control the level of the output power according to the requirement.

When all systems are modelled and masked with each other's, the conclusion comes that the energy conversion efficiency of the solar panel will be increased. The total energy converted by the system is also increased because in that advanced solar system we used the thermal panel, and the water cooling system that can helps to utilize the energy of the system. The heat loss will be reduced and that heat can be absorbing by the thermal panel and it would also convert that heat energy into the electrical energy. The water used in the cooling system can provide the hot water supply to the consumer for the different purpose and the environment will also not have polluted and the health and wealth both are secured. This technology increases the use of renewable energy sources at very low cost.

\section{References}

[1] Eveloy, V; Rodgers, P.; Bojanampati, S, "Enhancement of photovoltaic solar module performance for power generation in the Middle East," 2012 28th Annual IEEE semiconductor Thermal Measurement and Management Symposium (SEMI- THERM), pp. 87-97, 2012.

[2] Bojanampati, S; Rodgers, P; Eveloy, V, "Experimental assessment of flat-type photovoltaic module thermal behaviour," 2012 13th International Conference on
Thermal, Mechanical and Multi-Physics Simulation and Experiments in Microelectronics and Microsystems (EuroSimE), pp. 1/4 - 4/4, 2012.

[3] Xinqiang Xu; Meyers, M. M.; Sammakia, B.G.; Murray, BT, "Thermal modelling of hybrid concentrating PV/T collectors with tree-shaped channel networks cooling system," $201213^{\text {th }}$ IEEE Intersociety Conference on Thermal and Thermo mechanical Phenomena in Electronic Systems (IT herm), pp. 1131-113,2012.

[4] Chatterjee, S.; TamizhMani, G., "BAPV arrays: Sideby-side comparison with and without fan cooling," 2012 38th IEEE Photovoltaic SpeCialists Conference (PVSC), pp.537-542, 2012.

[5] Brandhorst, HW, Jr.; Rodiek, IA, "Solar-powered, modular, emergency/disaster response housing," 2009 34th IEEE Photovoltaic Specialists Conference (PVSC), pp.385-389, 2009.

[6] Christoph Hammerschmidt, "IBM reuses PV thermal energy for better efficiency", Electronic Engineering Times Europe.

[7] Welander, P., 1967, "00 the Oscillatory Instability of aDifferentially Heated Fluid Loop," Journal of Fluid Mechanics, Vol. 29, Part. 1, pp. 17-30.

[8] Madejski, J., and Mikielewicz, J., 1971, "Liquid Fin-A New Device for Heat Transfer Equipment," International Journal of Heat and Mass Transfer, Vol. 14, pp. 357-363.

[9] Creveling, H. F., et al., 1975, "Stability Characteristics of a Single-phase Free Convection Loop," Journal of Fluid Mechanics, Vol. 67, Part 1, pp. 65-84.

[10] Jones, G. F., 1986, "Heat Transfer in a Liquid Convective Diode," Journal of Solar Energy Engine\&=, Vol. 108, pp. 163-171.

\section{Author Profile}

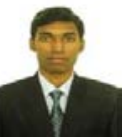

Chandra Kant Sahu is currently pursuing B. Tech.M. Tech. (dual degree) in Electrical and Electronics Engineering in Lovely Professional University, Phagwara, Punjab. And currently working on research for improvement of solar panel conversion efficiency.

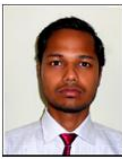

Saurabh Patel is currently pursuing B. Tech.-M. Tech. (dual degree) in Electrical and Electronics Engineering in Lovely Professional University, Phagwara, Punjab. And currently working on research for PI controller using advanced fuzzy techniques. 